\title{
Effect of dental implantation on the hard and soft tissues around the adjacent natural teeth
}

\section{Wpływ implantacji na twarde i miękkie tkanki otaczające sąsiednie zęby}

\author{
Seyed Reza Arabi ${ }^{1, A-E}$, Arash Shishehian ${ }^{2, B, E}$, Sara Khazaei ${ }^{2, D, E}$, Banafsheh Poormoradi ${ }^{3, E}$, Samaneh Abbasi ${ }^{2}, \mathrm{D}, \mathrm{E}$, Hanif Allahbakhshi ${ }^{4}, \mathrm{~A}, \mathrm{C}$, \\ Farnoush Fotovat ${ }^{2,4, A-F}$, Javad Faradmal ${ }^{5, C}$ \\ ${ }^{1}$ Private Dental Practice, Hamadan, Iran \\ ${ }^{2}$ Department of Prosthodontics, School of Dentistry, Hamadan University of Medical Sciences, Iran \\ ${ }^{3}$ Department of Periodontology, School of Dentistry, Hamadan University of Medical Sciences, Iran \\ ${ }^{4}$ Department of Prosthodontics, School of Dentistry, Kashan University of Medical Sciences, Iran \\ ${ }^{5}$ Department of Biostatistics and Epidemiology, School of Public Health, Hamadan University of Medical Sciences, Iran \\ A - research concept and design; $\mathrm{B}$ - collection and/or assembly of data; $\mathrm{C}$ - data analysis and interpretation; \\ $D$ - writing the article; $E$ - critical revision of the article; $F$ - final approval of the article
}

\section{Address for correspondence}

Farnoush Fotovat

E-mail: ffotovat96@gmail.com

Funding sources

None declared

Conflict of interest

None declared

\section{Acknowledgements}

This investigation was approved and financially supported by the Vice-Chancellor for Research and Technology of Hamadan University of Medical Sciences, Iran.

Received on February 1, 2019

Reviewed on May 30, 2019

Accepted on July 15, 2019

Published online on November 26, 2019

Cite as

Arabi SR, Shishehian A, Khazaei S, et al. Effect of dental implantation on the hard and soft tissues around the adjacent natural teeth. Dent Med Probl. 2019;56(4):331-336. doi:10.17219/dmp/110714

DOI

10.17219/dmp/110714

Copyright

๑ 2019 by Wroclaw Medical University

This is an article distributed under the terms of the

Creative Commons Attribution 3.0 Unported License (CC BY 3.0)

(https://creativecommons.org/licenses/by/3.0/)

\begin{abstract}
Background. Dental implantation has become widespread for esthetic and functional rehabilitation following single tooth loss as a preferred alternative to conventional tooth-supported restorations. The main advantage of dental implant placement is that it does not require the preparation of the adjacent sound teeth.

Objectives. The aim of this cohort study was to assess the effect of dental implantation on the hard and soft tissues around the adjacent natural teeth.

Material and methods. In this historical cohort, $34^{\prime}{\text { connect-type' }{ }^{\prime} B R^{\circledR}}$ implants (bone level), $4 \mathrm{~mm}$ in diameter, were submerged in the intact bone of 22 patients $(7$ males and 15 females). The intraoral and extraoral clinical examination as well as periapical radiography were carried out preoperatively or right after surgery (baseline), at 3 months postoperatively (the time of prosthetic delivery), and at 3 and 6 months after prosthetic delivery. The data was analyzed using the Friedman test (due to the non-normal distribution of the data). In case of presence of a significant difference, pairwise comparisons were performed using the post-hoc Wilcoxon test with the Bonferroni correction. All statistical analyses were performed with a 95\% confidence interval (CI) using the SPSS for Windows, v. 16.0 software. The $p$-value $<0.05$ was considered statistically significant.
\end{abstract}

Results. The distance from the cementoenamel junction (CE) of the adjacent teeth to the bone crest significantly increased at different postoperative time points compared to baseline $(p<0.001)$. The changes in the papillae of the adjacent teeth were also significant at different postoperative time points $(p=0.04)$. The pocket depth of the adjacent teeth increased, although the value at 3 months postoperatively was not significantly different from the baseline value $(p=0.842)$. The distance from the implant shoulder to the bone crest of the adjacent teeth significantly increased at different postoperative time points compared to baseline $(p<0.001)$.

Conclusions. Our results indicate that implant surgery significantly affects the soft and hard tissues around the adjacent natural teeth.

Key words: dental implants, alveolar bone loss, dental papilla

Słowa kluczowe: implanty dentystyczne, zanik kości wyrostka zębodołowego, brodawka zębowa 


\section{Introduction}

Dental treatment is applied with the aim of restoring oral and dental function, comfort, esthetics, speech, and tissue health. ${ }^{1}$ The use of dental implants is increasing because of the growth of the elderly population and tooth loss due to aging, the failure of conventional fixed partial dentures, the poor performance of removable dentures, the psychological consequences of tooth loss, and the predictable long-term results of implant-supported restorations. ${ }^{1,2}$ Thus, dental implantation has become a common alternative to tooth-supported restorations to regain esthetics and function after single tooth loss. The main advantage of dental implant placement is that it does not require the preparation of the adjacent sound teeth. ${ }^{3}$

Oral rehabilitation by dental implant placement in the esthetic zone is among the most complex treatment procedures, with the aim of creating optimal esthetics. With regard to the soft tissue contour, it is imperative to achieve a uniform gingival margin with no significant change in gingival height. ${ }^{4}$ The presence of an adequate papilla and a convex contour over the alveolar crest are also important. The incision line, the flap design and the suturing technique are important surgical factors influencing the final results. The results should be predictable and stable. They depend on the interaction of several variables, including biological factors (the anatomy of the region and the host response), surgical factors (the three-dimensional (3D) implant position), implant-related factors (the implant surface and design), and prosthetic factors. ${ }^{5,6}$ The interdental area is composed of the contact area, the interproximal embrasure and the interproximal dentogingival complex. This area is the primary site for the development of periodontitis and carious lesions, since it is prone to microbial plaque accumulation. The loss of the interproximal papilla can cause functional problems in the anterior maxilla, and lead to serious phonetic and esthetic problems. ${ }^{6,7}$

The level of papillae around the single-tooth implants in the anterior maxilla is mainly affected by the level of the interproximal bone crest around the adjacent teeth. On the other hand, the level of the facial gingival margin is affected by a number of factors, including the peri-implant gingival biotype, the facial bone level, implant fixture angulation, and the level of the interproximal bone crest. ${ }^{7}$ Moreover, evidence shows that the level of the bone crest affects the soft tissue height. ${ }^{8}$ Several classifications have been suggested to assess and quantify the loss or regeneration of the interdental or interimplant papilla. Jemt's classification is a commonly used index for the assessment of mesial and distal papillae. ${ }^{9}$ According to this classification, a score of 0 indicates the absence of a papilla and the soft tissue contour around the implant restoration. A score of 1 indicates the presence of less than half of the papillary height and a concave soft tissue contour between the single-tooth implant crown and the adjacent teeth.
A score of 2 represents the presence of half or more of the papillary height; however, the papilla is not located above the interdental contact area at any point. A score of 3 indicates that the papilla fills the entire interproximal space and is in good harmony with the adjacent papillae; an ideal soft tissue contour is also present. A score of 4 indicates the presence of a hyperplastic papilla which covers a large portion of the single-tooth implant restoration or the adjacent teeth; the soft tissue contour is more or less irregular. ${ }^{9}$

It is believed that soft and hard tissue changes around implant-supported fixed partial dentures occur in the first 6 months after 1-stage implant placement, and the pattern of tissue alterations is different between the tooth and the implant on the one hand and between 2 adjacent implants on the other. ${ }^{10}$ The magnitude of proximal bone loss between 2 adjacent implants is on average $0.6 \mathrm{~mm}$ at 6 months, whereas this value is less than $0.1 \mathrm{~mm}$ between the implant and the adjacent tooth. Evidence shows that further changes are not often observed in the period from 6 months to 3 years.

The aim of this study was to assess the effect of dental implantation on the hard and soft tissues around the adjacent natural teeth.

\section{Materials and methods}

The study design was approved by the Research and Ethics Committee of Hamadan University of Medical Sciences, Iran (IR.UMSHA.REC.1395.324). In this historical cohort, 34 implants were placed in 22 patients $(7$ males and 15 females) who had an edentulous region adjacent to the natural teeth. Written informed consent was obtained from the patients who were willing to participate in the study. Data forms were filled out by the patients and the clinical examination was carried out. The diagnostic radiographic examination included periapical radiography and cone-beam computed tomography (CBCT). The patients were followed up for 9 months following implant placement.

The exclusion criteria comprised the presence of all teeth, a restoration covering the cementoenamel junction (CEJ) of the teeth adjacent to the edentulous area, smoking, alcohol consumption, substance abuse, immunocompromised patients, patients with active periodontitis, those requiring guided bone regeneration, uncontrolled active systemic diseases, diabetes mellitus, hypertension, uncontrolled cardiac disease, radiotherapy, chemotherapy, the intake of immunosuppressive medications, and long-term steroid therapy.

In this study, 34 'connect-type' $\mathrm{TBR}^{\circledR}$ implants (bone level) (TBR Dental Group, Toulouse, France), $4 \mathrm{~mm}$ in diameter, were used. The implants were completely submerged in the intact bone. After ensuring the presence of the sufficient width of the keratinized gingiva, a crestal 
incision was made with a surgical scalpel size 15 (KLS Martin GmbH + Co. KG, Freiburg im Breisgau, Germany). A full-thickness flap was elevated so that the papilla of the adjacent tooth could also be reflected. No crestal ostectomy was performed on the patients, and the preparation of the implant site for fixture installation was carried out according to the manufacturer's instructions. We used figure-8 sutures (silk 4-0; Supa Medical Devices Co., Tehran, Iran). One week after surgery, the sutures were removed. The patients received $500 \mathrm{mg}$ amoxicillin (Farabi Pharmaceutical Company, Isfahan, Iran) thrice daily (TID), $600 \mathrm{mg}$ ibuprofen (Zahravi Pharmaceutical Co., Tehran, Iran) TID and $0.2 \%$ chlorhexidine mouthwash (Behsa Pharma Co., Arak, Iran) twice daily (BID) for 1 week postoperatively. ${ }^{11}$ The prosthetic restoration was delivered 3 months postoperatively. The digital periapical radiographs of the implant and of the adjacent teeth were obtained in all patients before surgery or right after surgery (baseline), and also at 3 months (at the time of prosthetic delivery), 6 months and 9 months postoperatively (Fig. 1). All radiographs were obtained by the same $\mathrm{X}$-ray unit in order to standardize the exposure settings and projections. Variables in this study included the presence of papillae around the natural teeth adjacent to the implant according to Jemt's classification, and the pocket depth at the proximal, buccal and palatal/lingual surface of the adjacent teeth measured with a Williams probe (Hu-Friedy Mfg. Co., LLC, Chicago, USA). The maximum
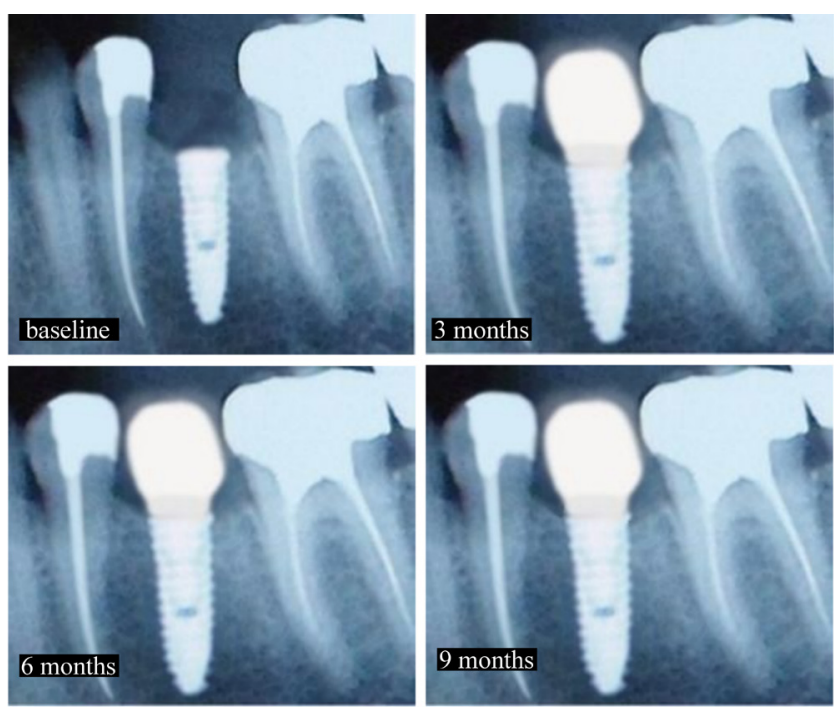

Fig. 1. Standard periapical radiographs at different time points (baseline, and 3,6 and 9 months postoperatively) value was recorded in millimeters, and eventually the distance from the implant shoulder to the bone crest as well as the distance from the bone crest to the CEJ of the adjacent teeth were measured using a digital caliper.

The data was analyzed using SPSS for Windows, v. 16 (SPSS Inc., Chicago, USA). Since the data was not normally distributed, the Friedman test was used to compare the changes in the respective variables. In case of a significant difference, pairwise comparisons were carried out using the post-hoc Wilcoxon test. The generalized estimating equation model was used to analyze Jemt's classification at different time points. The Bonferroni adjustment was also applied. All of the analyses were performed with a confidence interval (CI) of 95\%. The $p$-values $<0.05$ were considered statistically significant.

\section{Results}

Of the patients, $31.82 \%$ were males and $68.18 \%$ were females. The mean age of the patients was 39.23 years. The frequency distribution of implants in terms of position was as follows: $58.8 \%$ in the maxilla; $41.2 \%$ in the mandible; $32.35 \%$ in the anterior region; and $67.65 \%$ in the posterior region of the jaws.

As shown in Table 1, the distance from the CEJ of the adjacent teeth to the bone crest at different time points significantly increased compared to baseline $(p<0.001)$. The pairwise comparisons of the distance from CEJ to the bone crest at different time points revealed that the increase in this distance was statistically significant at 6 months postoperatively compared to 3 months and at 9 months postoperatively compared to 3 months $(p<0.001)$. However, the increase at 9 months postoperatively compared to 6 months was not statistically significant $(p=0.583)$ (Table 2).

As shown in Tables 1 and 2, the changes in the pocket depth of the adjacent teeth showed an ascending trend starting at 3 months postoperatively $(p<0.001)$. The pocket depth at 3 months postoperatively decreased compared to baseline, but the change was not significant $(p=0.842)$. The distance from the implant shoulder to the bone crest around the implant significantly increased at different time points postoperatively compared to baseline $(p<0.001)$. The pairwise comparisons of this parameter at different time points revealed a significantly ascending trend $(p<0.001)$ (Tables 1,2$)$.

Table 1. Mean changes in the level of the cementoenamel junction (CEJ), pocket depth and shoulder-to-crest distance at different postoperative time points compared to the baseline values (the Friedman test)

\begin{tabular}{|l|c|ccc|c|}
\multicolumn{1}{c|}{ Variables } & Baseline & 3 months & 6 months & 9 months & p-value \\
\hline CEJ $[\mathrm{mm}]$ & $3.05 \pm 0.77$ & $3.15 \pm 0.73$ & $3.32 \pm 0.74$ & $3.32 \pm 0.73$ & $<0.001$ \\
Pocket depth $[\mathrm{mm}]$ & $3.83 \pm 0.90$ & $3.81 \pm 0.91$ & $4.31 \pm 0.81$ & $4.69 \pm 0.76$ \\
Shoulder-to-crest distance $[\mathrm{mm}]$ & $0.24 \pm 0.13$ & $0.47 \pm 0.14$ & $0.64 \pm 0.18$ & $0.74 \pm 0.19$ \\
\hline
\end{tabular}

Data presented as mean \pm standard deviation (SD). 
Table 2. Pairwise comparisons of the mean differences for the variables studied at different time points

\begin{tabular}{|c|c|c|c|c|c|c|}
\hline \multirow{2}{*}{ Time } & \multicolumn{2}{|l|}{ CEJ } & \multicolumn{2}{|c|}{ Pocket depth } & \multicolumn{2}{|c|}{ Shoulder-to-crest distance } \\
\hline & mean difference $\pm S E$ & $p$-value & mean difference $\pm S E$ & $p$-value & mean difference $\pm S E$ & $p$-value \\
\hline 3 months-baseline & $0.103 \pm 0.33$ & $<0.006$ & $-0.021 \pm 0.890$ & $<0.842$ & $0.228 \pm 0.024$ & $<0.001$ \\
\hline 6 months-baseline & $0.273 \pm 0.36$ & $<0.001$ & $0.479 \pm 0.107$ & $<0.001$ & $0.397 \pm 0.035$ & $<0.001$ \\
\hline 9 months-baseline & $0.276 \pm 0.43$ & $<0.001$ & $0.853 \pm 0.109$ & $<0.001$ & $0.499 \pm 0.036$ & $<0.001$ \\
\hline 6 months -3 months & $0.171 \pm 0.34$ & $<0.001$ & $0.500 \pm 0.088$ & $<0.001$ & $0.169 \pm 0.028$ & $<0.001$ \\
\hline 9 months -3 months & $0.174 \pm 0.35$ & $<0.001$ & $0.874 \pm 0.103$ & $<0.001$ & $0.270 \pm 0.027$ & $<0.001$ \\
\hline 9 months -6 months & $0.003 \pm 0.35$ & $<0.583$ & $0.374 \pm 0.104$ & $<0.002$ & $0.101 \pm 0.025$ & $<0.001$ \\
\hline
\end{tabular}

CEJ - cementoenamel junction; SE - standard error; Bonferroni adjustment $a=0.008$.

As shown in Table 3, the frequency of Jemt's classification score 0 in the adjacent teeth decreased postoperatively compared to baseline. The frequency of score 1 at 3 months postoperatively was the same as at baseline, but it decreased at 6 months postoperatively and increased at 9 months postoperatively compared to baseline. The frequency of score 2 in the adjacent teeth increased at 3 months postoperatively (the time of prosthetic delivery) compared to baseline, and then remained constant (Table 3). The change in the presence of papillae around the adjacent teeth was statistically significant at different postoperative time points $(p=0.04)$ (Table 4$)$.

In general, according to Jemt's classification for the adjacent teeth, the presence of papillae increased at 3 months postoperatively (the time of prosthetic delivery; $85.3 \%$ ), at 6 months postoperatively $(79.4 \%)$ and at 9 months postoperatively (88.2\%) compared to baseline (76.5\%).

Table 3. Frequency of Jemt's classification scores at baseline, and at 3,6 and 9 months postoperatively

\begin{tabular}{|l|c|c|c|c|}
\hline Jemt's index & Baseline & 3 months & 6 months & 9 months \\
\hline 0 & $8(23.5)$ & $5(14.7)$ & $7(20.6)$ & $4(11.8)$ \\
1 & $24(70.6)$ & $24(70.6)$ & $22(64.7)$ & $25(73.5)$ \\
2 & $2(5.9)$ & $5(14.7)$ & $5(14.7)$ & $5(14.7)$ \\
\hline
\end{tabular}

Data presented as number (percentage).

Table 4. Comparison of the frequency of Jemt's classification scores at different time points

\begin{tabular}{|ll|}
\multicolumn{1}{c}{ Time points } & $p$-value \\
\hline Baseline-3 months-6 months-9 months & $0.040^{* *}$ \\
Baseline-3 months & $0.085^{*}$ \\
Baseline-6 months & $0.338^{*}$ \\
Baseline-9 months & $0.036^{*}$ \\
3 months-6 months & $0.634^{*}$ \\
3 months-9 months & $0.798^{*}$ \\
6 months-9 months & $0.173^{*}$ \\
\hline
\end{tabular}

* $a=0.008 ;{ }^{* *} a=0.05$ (Bonferroni adjustment).

\section{Discussion}

Commonly used implant success criteria mainly focus on the functional and technical aspects of dental implants, including successful osseointegration, achieving a stable peri-implant bone margin and a high survival rate. However, in the case of implant-supported restorations in the anterior region, the success of the treatment depends on the esthetic results as well. ${ }^{12}$ The expectations of optimal esthetic results create a challenge for implant treatment in the anterior maxilla, especially in patients with scalloped margins. On the other hand, coronal reconstruction should be performed with regard to the crowns of the adjacent natural teeth. ${ }^{4}$ Evidence shows that the soft tissue margin around the natural teeth is determined by the attachment of the connective tissue to the root, the bone height, the alveolar bone support, and the soft tissue thickness. However, it seems that soft tissue appearance in the proximal regions around the single-tooth implants is influenced by the periodontal support of the adjacent natural teeth. ${ }^{3}$ The esthetic outcome of implant treatment is not merely related to the crown shape; the topography and appearance of the surrounding soft tissues also affect the esthetic results. ${ }^{13}$ Chang et al. observed that the soft tissue margin at the proximal and facial aspects of the implant was positioned much more apically than the gingival margin at similar sites in the adjacent teeth. ${ }^{3}$ Such differences may manifest themselves immediately after crown delivery due to the loss of the bone height following tooth extraction. However, soft tissue marginal recession may also occur following crown placement. ${ }^{14-16}$ Moreover, Jemt et al. showed that the gingival margins of the natural teeth around the single-tooth implants were at a higher risk of gingival recession in the long term compared to the untreated natural teeth. ${ }^{17}$

In the present study, we made efforts to standardize the status of the patients. As mentioned earlier, the patients had no systemic diseases and were generally healthy, did not have active periodontitis, and did not require guided bone regeneration. They were non-smokers and had no parafunctional habits. Also, they had good oral hygiene, did not use any immunosuppressive medications, were not alcoholics, and did not report substance abuse. Furthermore, they had at least 1 edentulous region with the adjacent natural teeth which did not have restorations covering CEJ. All implants were placed by the same expert surgeon. ${ }^{18}$ A total of 22 patients participated in the study and received 34 'connect-type' TBR implants (bone level), $4 \mathrm{~mm}$ in diameter, which were totally submerged in the intact bone. 
The distance from the CEJ of the tooth mesial to the implant to the bone crest increased by $0.103 \mathrm{~mm}$ at 3 months postoperatively, by $0.273 \mathrm{~mm}$ at 6 months postoperatively and by $0.276 \mathrm{~mm}$ at 9 months postoperatively compared to baseline. The distance from CEJ to the bone crest had an ascending trend up to 6 months postoperatively, which was probably due to the effects of flap elevation and the retraction of the periosteum. ${ }^{1}$ Our findings in this respect are consistent with those of Meijndert et al., who observed that the bone loss of the teeth around the implants was small but statistically significant for up to 1 month after treatment. ${ }^{19}$ Block et al., however, evaluated 76 patients and divided them into 2 groups. ${ }^{18}$ The patients in group 1 had lost 1 maxillary tooth (premolar, canine, lateral incisor, or central incisor) and underwent immediate socket preservation by bone grafting followed by implant placement, and received a temporary restoration for 4 months. Group 2 underwent immediate implant placement and received a temporary restoration. The patients were examined at baseline, and at $6,12,18$, and 24 months. The researchers concluded that the bone level around the teeth adjacent to the implant did not change over time and found no significant differences in the bone level between the 2 groups. ${ }^{18}$ Immediate implant placement had no significant effect on the level of bone around the adjacent teeth and delayed implant placement had similar effects to immediate implant placement. ${ }^{20}$ The difference between our study and that of Block et al. may be due to the different treatment protocols employed and the scheduled follow-ups. As shown in previous studies, the maximum changes occur in the first 6 months following treatment ( $1^{\text {st }}$ phase $) .{ }^{8}$ In other words, osseointegration and the adaptation of the marginal soft tissue occur separately in 2-stage implant placement, whereas these steps occur simultaneously in the first 3-6 months following 1-stage implant placement. $^{21}$ The current results revealed that the frequency of score 0 decreased in the teeth adjacent to the implants over time compared to baseline. The frequency of score 1 remained constant until 3 months after surgery, but decreased at 6 months and increased at 9 months postoperatively compared to baseline. The frequency of score 2 in the teeth adjacent to the implants increased at 3 months compared to baseline and remained constant thereafter. Our results are in agreement with the findings of previous studies. Chang et al. evaluated 20 patients and observed a statistically significant increase in the papillary index in both the mesial and distal areas over time. ${ }^{3}$ Scores $0-1$ were obtained at the time of placing a crown in 12 out of 26 areas (46\%), whereas in the follow-up examination, only 2 areas (8\%) were scored $0-1$. Moreover, only 1 interdental area was completely filled by the papilla at the time of crown placement (score 3 ), whereas this value increased to 11 regions (42\%) during the follow-up sessions. Cosyn and De Rouck found a significant difference in the mesial papillary height between the implant and its adjacent natural teeth. ${ }^{22}$ Shorter papillae
(0.4 $\mathrm{mm}$ on average) were observed at the implant site and the distal papillae were on average $1 \mathrm{~mm}$ shorter at the implant site compared to the adjacent teeth. ${ }^{22}$ The results of those studies are in agreement with ours in terms of increases in the papillary index. However, the studies differ regarding the shorter height of the papillae distal to the implants compared to the mesial papillae. This controversy can be attributed to the difference in the sites studied, the teeth replaced with dental implants and the type of surgical procedure. As in our study, Palmer et al. and Lee et al. found no significant difference in the prevalence of complete papillae in the mesial and distal areas, which may be due to the anatomical differences in the embrasure space. ${ }^{21,23}$ Moreover, the distal contact point is usually located more apically than the mesial contact point, by $1.5 \mathrm{~mm}$ on average; this anatomical difference can affect the shape of papillae. ${ }^{21}$

Our findings revealed that the pocket depth of the teeth mesial to the dental implants did not change for 3 months postoperatively, but later showed a significant increase, which may be due to the tissue reaction to the prosthetic restoration, the patient's oral hygiene status or similar issues. ${ }^{24}$ Avivi-Arber and Zarb evaluated 41 patients who were followed up for 1-8 years. ${ }^{25}$ Examinations performed 1 year after implant loading revealed that the mean annual bone loss was $0.03 \mathrm{~mm}$ in the mesial region and $0.11 \mathrm{~mm}$ in the distal region for all implants. ${ }^{25}$ That study also showed an ascending trend in bone loss postoperatively; however, the magnitude of bone loss was smaller than the value reported in our study. This difference may be due to the type of surgical procedure (which was 2-step in the study by Avivi-Arber and Zarb), the time of assessment, the location of the implant, and the implant design. ${ }^{25}$ Kourkouta et al. indicated that crestal bone loss increased following implant loading, but in our study, this value was smaller. ${ }^{24}$ The comparison of their results with ours is difficult, since the treatment sites and the assessment time points were different in the 2 studies. Moreover, bone loss between the implant and the tooth (due to the presence of the natural tooth) was smaller than that between 2 adjacent implants. ${ }^{24}$ On the other hand, our results were different from those of Grunder, who evaluated 10 patients that received single-tooth implants in the anterior maxilla and did not have periodontal disease. ${ }^{26}$ Their results indicated that no areas around the natural teeth adjacent to the implants had a probing depth $>4 \mathrm{~mm}$ before or within 1 year after treatment. Comparing their results with ours, there are differences in the methodology and the implant sites. In the present study, the distance from the implant shoulder to the first bone-implant contact at the mesial and distal surfaces was measured on radiographs using a digital caliper. The results showed that the distance from the implant shoulder to the bone crest around the implant significantly increased at different time points postoperatively compared to baseline. Similarly, some studies have demonstrated that when the implant shoulder is placed 
subcrestally, greater bone loss occurs around the implant neck compared to the situation where the implant is placed at the level of the alveolar crest. ${ }^{27}$

We should mention that the small size of the study group is a limitation of our study. The results should be re-evaluated in a study with a larger sample size.

\section{Conclusions}

The results of our study indicate that implant surgery significantly affects the soft and hard tissues around the adjacent natural teeth.

\section{ORCID iDs}

Seyed Reza Arabi (1) https://orcid.org/0000-0003-0237-8923 Arash Shishehian (1) https://orcid.org/0000-0003-4338-3745 Sara Khazaei (1) https://orcid.org/0000-0001-8589-8611 Banafsheh Poormoradi (i) https://orcid.org/0000-0001-5970-6727 Samaneh Abbasi (1) https://orcid.org/0000-0003-3366-7111 Hanif Allahbakhshi (1) https://orcid.org/0000-0002-1430-6225 Farnoush Fotovat (1) https://orcid.org/0000-0002-7490-1675 Javad Faradmal ํㅣ https://orcid.org/0000-0001-5514-3584

\section{References}

1. Guillaume B. Dental implants: A review. Morphologie. 2016;100(331): 189-198.

2. Jablonowski L, Matthes R, Duske K, Kocher T. Perspectives in dental implantology. In: Metelmann HR, von Woedtke T, Weltmann KD, eds. Comprehensive Clinical Plasma Medicine: Cold Physical Plasma for Medical Application. Cham, Switzerland: Springer; 2018:319-330.

3. Chang M, Wennström JL, Odman P, Andersson B. Implant supported single-tooth replacements compared to contralateral natural teeth. Crown and soft tissue dimensions. Clin Oral Implants Res. 1999;10(3):185-194.

4. Schnutenhaus S, Martin T, Dreyhaupt J, Rudolph H, Luthardt RG. Dimensional changes of the soft tissue after alveolar ridge preservation with a collagen material. A clinical randomized trial. Open Dent J. 2018;12:389-399.

5. Rokn A, Bassir SH, Rasouli Ghahroudi AA, Kharazifard MJ, Manesheof R. Long-term stability of soft tissue esthetic outcomes following conventional single implant treatment in the anterior maxilla: 10-12-year results. Open Dent J. 2016;10:602-609.

6. Sorni-Bröker $M$, Peñarrocha-Diago $M$, Peñarrocha-Diago $M$. Factors that influence the position of the peri-implant soft tissues: A review. Med Oral Patol Oral Cir Bucal. 2009;14(9):e475-e479.

7. Nisapakultorn K, Suphanantachat S, Silkosessak O, Rattanamongkolgul $S$. Factors affecting soft tissue level around anterior maxillary single-tooth implants. Clin Oral Implants Res. 2010;21(6):662-670.

8. Chang $M$, Wennström JL. Peri-implant soft tissue and bone crest alterations at fixed dental prostheses: A 3-year prospective study. Clin Oral Implants Res. 2010;21(5):527-534.

9. Jemt T. Regeneration of gingival papillae after single-implant treatment. Int J Periodontics Restorative Dent. 1997;17(4):326-333.

10. Suárez-López Del Amo F, Lin GH, Monje A, Galindo-Moreno P, Wang HL. Influence of soft tissue thickness on peri-implant marginal bone loss: A systematic review and meta-analysis. J Periodontol. 2016;87(6):690-699.

11. Newman MG, Takei H, Klokkevold PR, Carranza FA. Carranza's Clinical Periodontology. $11^{\text {th }}$ ed. New York, NY: Elsevier Health Sciences; 2011:735.

12. Schropp L, Isidor F, Kostopoulos L, Wenzel A. Interproximal papilla levels following early versus delayed placement of single-tooth implants: A controlled clinical trial. Int J Oral Maxillofac Implants. 2005;20(5):753-761.

13. Reikie DF. Esthetic and functional considerations for implant restoration of the partially edentulous patient. J Prosthet Dent. 1993;70(5):433-437.
14. Adell R, Lekholm U, Rockler B, et al. Marginal tissue reactions at osseointegrated titanium fixtures: (I). A 3-year longitudinal prospective study. Int J Oral Maxillofac Surg. 1986;15(1):39-52.

15. Apse P, Zarb GA, Schmitt A, Lewis DW. The longitudinal effectiveness of osseointegrated dental implants. The Toronto Study: Peri-implant mucosal response. Int J Peridontics Restorative Dent. 1991;11(2):94-111.

16. Bengazi F, Wennström JL, Lekholm U. Recession of the soft tissue margin at oral implants. A 2-year longitudinal prospective study. Clin Oral Implants Res. 1996;7(4):303-310.

17. Jemt T, Ahlberg G, Henriksson K, Bondevik O. Changes of anterior clinical crown height in patients provided with single-implant restorations after more than 15 years of follow-up. Int J Prosthodont. 2006;19(5):455-461.

18. Block MS, Mercante DE, Lirette D, Mohamed W, Ryser M, Castellon P. Prospective evaluation of immediate and delayed provisional single tooth restorations. J Oral Maxillofac Surg. 2009;67(11 Suppl):89-107.

19. Meijndert L, Raghoebar GM, Meijer HJ, Vissink A. Clinical and radiographic characteristics of single-tooth replacements preceded by local ridge augmentation: A prospective randomized clinical trial. Clin Oral Implants Res. 2008;19(12):1295-1303.

20. Brägger U, Häfeli U, Huber $\mathrm{B}$, Hämmerle $\mathrm{CH}$, Lang NP. Evaluation of postsurgical crestal bone levels adjacent to non-submerged dental implants. Clin Oral Implants Res. 1998;9(4):218-224.

21. Palmer RM, Farkondeh N, Palmer PJ, Wilson RF. Astra Tech singletooth implants: An audit of patient satisfaction and soft tissue form. J Clin Periodontol. 2007;34(7):633-638.

22. Cosyn J, De Rouck T. Aesthetic outcome of single-tooth implant restorations following early implant placement and guided bone regeneration: Crown and soft tissue dimensions compared with contralateral teeth. Clin Oral Implants Res. 2009;20(10):1063-1069.

23. Lee DW, Huh JK, Park KH, Chai JK, Kim CK, Moon IS. Comparison of interproximal soft tissue height for single implants and contralateral natural teeth. Clin Oral Implants Res. 2009;20(12):1320-1325.

24. Kourkouta S, Dedi KD, Paquette DW, Mol A. Interproximal tissue dimensions in relation to adjacent implants in the anterior maxilla: Clinical observations and patient aesthetic evaluation. Clin Oral Implants Res. 2009;20(12):1375-1385.

25. Avivi-Arber L, Zarb GA. Clinical effectiveness of implant-supported single-tooth replacement: The Toronto Study. Int J Oral Maxillofac Implants. 1996;11(3):311-321.

26. Grunder U. Stability of the mucosal topography around singletooth implants and adjacent teeth: 1-year results. Int $J$ Periodontics Restorative Dent. 2000;20(1):10-17.

27. Pradeep A, Karthikeyan B. Peri-implant papilla reconstruction: Realities and limitations. J Periodontol. 2006;77(3):534-544. 